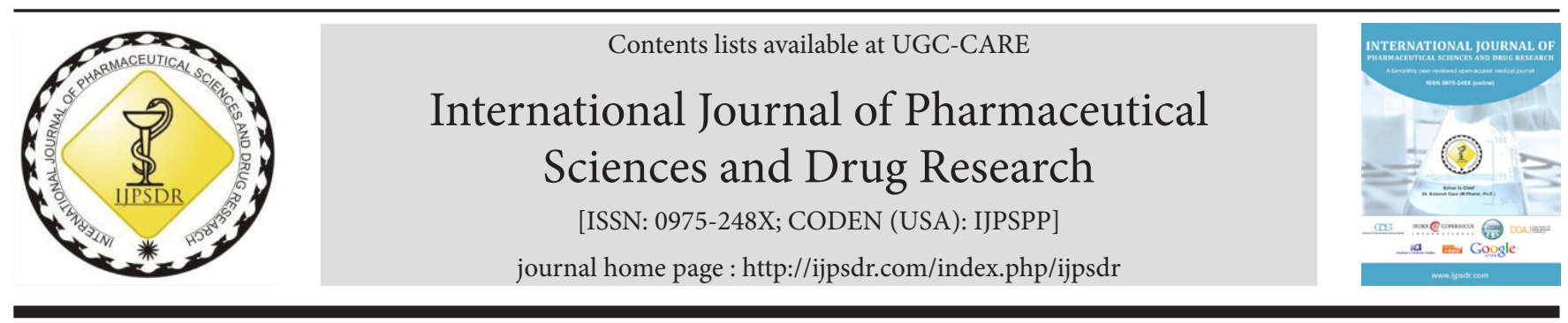

Research Article

\title{
Evaluation of In vitro Antioxidant Activity and High-Performance Thin-Layer Chromatography Finger Printing Analysis of Physalis peruviana Fruits
}

\author{
Saratha Venkatesan ${ }^{1}$, Ambiga Somasundaram ${ }^{2 *}$, Sangavi Rengaraj ${ }^{1}$ \\ ${ }^{1}$ Department of Biochemistry, Sengamala Thayaar Educational Trust Women's College, Sundarakkottai, Mannargudi, Thiruvarur-614016, \\ Tamil Nadu, India \\ ${ }^{2}$ Department of Biochemistry, School of Arts and Science, PRIST University, Thanjavur-613403, Tamil Nadu, India
}

\begin{tabular}{l} 
A R T I C L E I N F O \\
\hline Article history: \\
Received: 24 April, 2020 \\
Revised: 25 June, 2020 \\
Accepted: 04 July, 2020 \\
Published: 30 July, 2020 \\
Keywords: \\
Antioxidant, DPPH, \\
High-performance thin-layer \\
chromatography (HPTLC), \\
Physalis peruviana. \\
D0I: \\
10.25004/IJPSDR.2020.120411
\end{tabular}

\section{INTRODUCTION}

In the plethora of practical sciences, organic chemistry has a relatively young history, has emerged as a well-defined discipline less than two centuries age. But, its growth has been exceptional, and it has been given birth to many sub-divisions. The known organic compounds include not only those that possess a natural origin, but also a large number of synthesized in laboratories all over the world. Plants are known to contain innumerable biologically active compounds. Plant material produces secondary metabolite or polyphenolic compounds, like flavonoids, anthocyanidins, alkaloids, glycosides, phenolic acid, and tannins, which are the important sources of drug, like antioxidant, anti-cancer, etc. ${ }^{[1]}$

Free oxygen radicals possess an unpaired electron; it can be negative, positive, or neutral charge. ${ }^{[2]}$ Free oxygen radicals have been involved in the pathogenesis of the development of atherosclerosis, different stages of cancer development, autoimmune destruction of beta cells, causes diabetes, impaired insulin action, the mediator of inflammatory damage in asthma, liver damage, nephrotoxicity, aging, neurodegenerative diseases, rheumatoid arthritis, oxidation of lens protein leading to cataract, etc. ${ }^{[3]}$ Antioxidants constitute the cellular mechanism of defense against the consequences

\footnotetext{
${ }^{*}$ Corresponding Author: Ambiga Somasundaram

Address: Department of Biochemistry, School of Arts and Science, PRIST University, Thanjavur-613403, Tamil Nadu, India

Email $\bowtie$ : ambigabio@gmail.com

Relevant conflicts of interest/financial disclosures: The authors declare that the research was conducted in the absence of any commercial or financial relationships that could be construed as a potential conflict of interest.

Copyright (C) 2020 Saratha Venkatesan et al. This is an open access article distributed under the terms of the Creative Commons AttributionNonCommercial-ShareAlike 4.0 International License which allows others to remix, tweak, and build upon the work non-commercially, as long as the author is credited and the new creations are licensed under the identical terms.
} 
of antioxidants are substances that may cause high concentrations of reactive species. There is evidence that these molecules prevent tumorigenesis and increase life span. ${ }^{[4]}$ Apart from the protective role as preventive agents against cancer development, there is evidence that antioxidant supplementation during chemotherapy has the potential to reduce dose-limiting toxicities in patients with cancer. ${ }^{[5]}$

The P. peruviana plant grows to approximately three feet in height, and is small and shrub-like, with velvety heart-shaped leaves and yellow, bell-shaped flowers. The calyx was expanded, after the flower falls, finally produced a straw-colored husk, much larger than the fruit it encloses. The fruit is small, with smooth, orange-yellow skin, and juicy flesh containing numerous small seeds. The fruit may contain between 150 to 300 seeds, with diameters ranging between $1 / 2$ " to 1 " in diameter, and weighing from 4 to 9 grams each. When fully ripe, the fruit is sweet but with a pleasing, grape-like flavor, often described as sweet and tart, with a hint of citrus. ${ }^{[6]}$

The main active component of vitamin $A$ is $\beta$-carotene, which is responsible for the orange color of the fruits. $P$. peruviana has vitamin $\mathrm{C}$ and $\beta$-carotene; it acts as an anticancerous agent, which prevents free radical accumulation in tissues. Especially, withanolides and physalis are very important biologically active components for anti-inflammatory, antimicrobial, antitumor, immunomodulatory, and antiparasitic properties. P. peruviana leaves, stems, fruits and/or whole plants possess antiproliferative and cytotoxic effects on different cancer cell lines, such as, colon cancer, chronic myeloid leukemia, lung, breast, and liver cancer ${ }^{[7-11]}$ Hence, the present investigation was planned to evaluate in vitro antioxidant activity and HPTLC fingerprinting analysis of P. peruviana fruits.

\section{Materials AND METhods}

\section{Extraction}

The fruits of $P$. peruviana were collected in the month of April 2018 from Pattukottai, Thanjavur District, Tamil Nadu, India. Primarily the fruits were washed several times with distilled water to remove the traces of impurities from the fruits. Fruits were spread out in a plain paper and shade dried atroom temperature for about 15 days, and made a fine powder using a grinder mixture. ${ }^{[12]}$ The powder materials were used for further analysis. The plant was identified with the help and authenticated by Dr. S. John Britto, RABINAT Herbarium and Centre for Molecular Systematics, St. Josephs College, Tiruchirappalli.

One hundred grams of powder was soaked in ethanol for 72 hours. The powder was filtered by means of no.1 Whatman filter paper. The extract was kept in a boiling water bath for removal of ethanol. The ethanol-free extract was evaluated for preliminary phytochemical screening and in vitro antioxidant activity.

\section{HPTLC Fingerprint Analysis of Ethanolic Extract of P. peruviana Fruits}

HPTLC analysis was performed by 3 to $8 \mu \mathrm{L}$ ( $250 \mathrm{ng}$ to $2,500 \mathrm{ng} / \mathrm{mL}$ ) of standard quercetin solution, and 20 to $30 \mu \mathrm{L}$ of test solutions were loaded in a silica gel 60 F254 HPTLC plate (E. Merck) of uniform thickness $0.2 \mathrm{~mm}$ using Linomat $\mathrm{V}$ sample applicator. The ascending mode was used for the development of TLC. Toluene:ethyl acetate:acetic acid:ethanol (2.5:7:0.25:0.25) as the mobile phase. HPTLC plate in the solvent system was developed up to a distance of $8 \mathrm{~cm}$; the plate was dried at $130^{\circ} \mathrm{C}$ for 2 to 3 minutes at room temperature (RT). Scanned the plate densitometrically at $254 \mathrm{~nm}$, using TLC Scanner III. The plate was observed at 254 and $366 \mathrm{~nm}$, under UV light using Camag REPROSTAR 3.

\section{Total Antioxidant Capacity}

Different concentration of extract $(50,100,150,200$, and $250 \mu \mathrm{g} / \mathrm{mL}$ ) was treated with $1 \mathrm{~mL}$ of reagent solution (0.6 mM sulfuric acid, $28 \mathrm{mM}$ sodium phosphate, and $4 \mathrm{mM}$ ammonium molybdate) in Eppendorf tube. The capped tube was incubated in the thermal block at $95^{\circ} \mathrm{C}$ for 90 minutes. After cooling to room temperature, the absorbance was measured at $695 \mathrm{~nm}$ against the blank. The total antioxidant capacity was compared with ascorbic acid as a standard.

$$
\begin{aligned}
\text { Antioxidant capacity }(\%) & =\text { A control }- \text { A test } / \text { A control } \\
\times & 100
\end{aligned}
$$

\section{DPPH Free Radical Scavenging Activity}

The DPPH is reacted with methanol or absolute ethanol to yield purple color DPPH radical. The presence of antioxidants, which include polyphenolic compounds and flavonoids in the sample, will scavenge the formed DPPH radical, and thereby a decreased color will be observed, which is spectrophotometrically measured at $517 \mathrm{~nm}$. To $0.5 \mathrm{~mL}$ of the DPPH radical solution, add $2 \mathrm{~mL}$ of the extract, and the reaction mixture is vortexes for 10 seconds, and allowed to stand at room temperature for 30 minutes. $^{[13]}$ The absorbance was recorded at $517 \mathrm{~nm}$, the $\%$ of inhibition was calculated. Ascorbic acid was used as a standard.

The DPPH was calculated as follows:

DPPH (\%) = Sample absorbance $/$ Blank absorbance $1 \times 100$

\section{Reducing Power Assay}

The reducing capacity of a chemical compound can be served as a remarkable measuring unit of its potent antioxidant activity. $1 \mathrm{~mL}$ of various concentrations (50, $100,150,200$, and $250 \mathrm{~g} / \mathrm{mL}$ ) of plant extracts were mixed with $2.5 \mathrm{~mL}$ phosphate buffer and $2.5 \mathrm{~mL}$ of potassium ferricyanide. The above solution was incubated for 20 minutes at $50^{\circ} \mathrm{C}$. Trichloroacetic acid $2.5 \mathrm{~mL}$ was added to the above solution; it was centrifuged for 10 minutes at $3,000 \mathrm{rpm} .2 .5 \mathrm{~mL}$ of supernatant was collected, and it was mixed with $2.5 \mathrm{~mL}$ of distilled water. Freshly prepared 
ferric chloride solution $0.5 \mathrm{~mL}$ was added to the above mixture, optical density was measured at $700 \mathrm{~nm} .{ }^{[13]}$

The reducing power assay was calculated according to the following equation

$$
\text { RPA (\%) }=\text { Test control } / \text { Test } \times 100
$$

\section{RESULTS}

The phytochemical analysis of ethanolic extract of $P$. peruviana fruits showed the presence of various phytoconstituents, like alkaloids, flavonoids, saponins, phenolics, tannins, and anthraquinones (Table 1).

\section{HPTLC Fingerprint Analysis of $P$. peruviana Fruits}

HPTLC is an important quality assessment tool for quantification and identification of chemical compounds in plant materials. The HPTLC procedure effectively quantified the sample extract. Initially, toluene:ethyl acetate:acetic acid:ethanol in varying ratios were tried. The mobile phase used was toluene:ethyl acetate:acetic acid:ethanol in the ratio 2.5:7:0.25:0.25 v/v/v, have good resolution with $\mathrm{Rf}=0.7$. The quantification of quercetin in the ethanolic extract of $P$. peruviana fruits is shown in Fig. 1, since there is only one peak seen, as shown in Fig. 2. The TLC plate spot of the entire chromatogram was visualized under UV light at $254 \mathrm{~nm}$ after derivation. A TLC plate of quercetin standard and ethanolic extract of $P$. peruviana fruits is shown in Fig. 3.

The Rf obtained for the P. peruviana fruit extract closely replicated the $\mathrm{Rf}$ found for standard quercetin, thus, making it ideal for the HPTLC fingerprint parameter. The chromatogram of standard quercetin and that of quercetin identified in P. peruviana fruit samples, are shown in Fig. 3. The respective Rf obtained from each sample are shown in Table 2. The peak corresponding to quercetin is $0.65,0.63,0.63,0.64,0.64$, and 0.64 , and the sample is $0.65,0.65,0.65,0.65,0.68$, and 0.64 . From the above data, sample and standard quercetin have the same retention

Table 1: Phytochemical screening of P. peruviana fruits

\begin{tabular}{lll}
\hline S. No. & Compounds & P. peruviana fruit extract \\
\hline 1 & Alkaloids & + \\
2 & Flavonoids & + \\
3 & Saponins & + \\
4 & Phenols & + \\
5 & Tannins & + \\
6 & Anthraquinones & + \\
7 & Glycosides & - \\
8 & Cardiac glycosides & - \\
9 & Terpenoids & - \\
10 & Carbohydrates & - \\
11 & Steroid & - \\
12 & Phlobatannins & - \\
13 & Quinones & - \\
\hline
\end{tabular}

factor. The calibration curve of standard quercetin is shown in Fig. 4. The percentage amount of quercetin in P. peruviana fruit extract was found to be $0.1863 \% \mathrm{w} / \mathrm{w}$, respectively.

\section{Total Antioxidant Scavenging Activity of Ethanolic Extract of $P$. peruviana Fruits}

The total antioxidant assay of $P$. peruviana fruit extracts was evaluated by phosphomolybdenum method. The P. peruviana fruit extract contains an antioxidant compound,
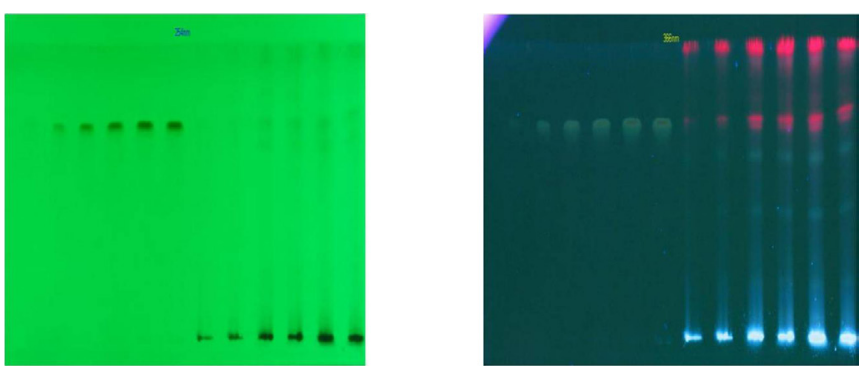

Fig. 1: Quantification of quercetin in ethanolic extract of P. peruviana fruits photo documentation under UV

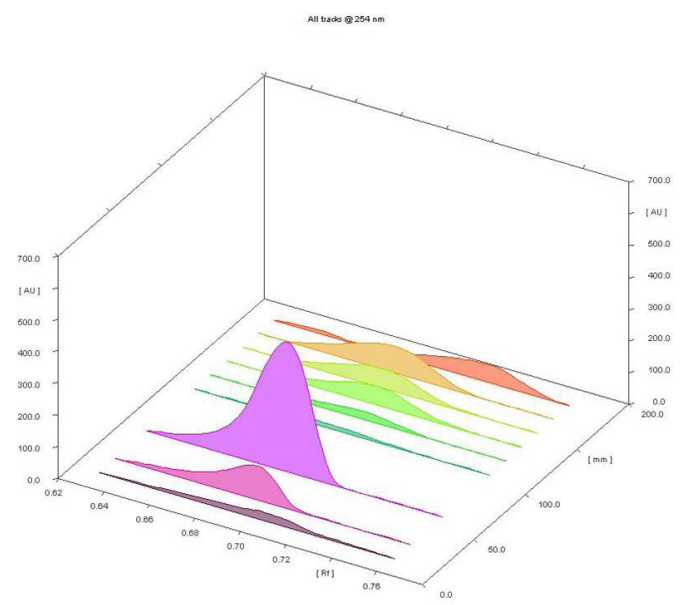

Fig. 2: HPTLC chromatogram of ethanolic extract of $P$. peruviana fruits 3D display at $254 \mathrm{~nm}$

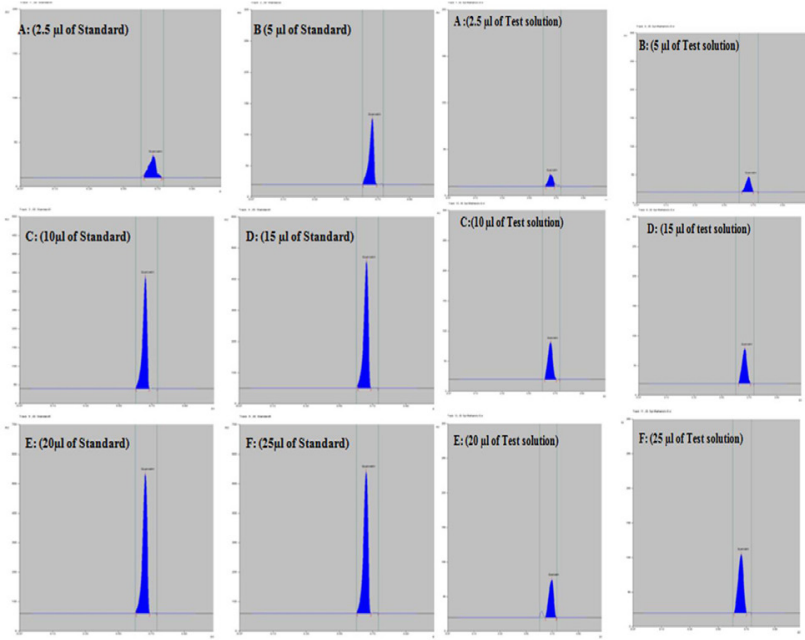

Fig. 3: HPTLC chromatogram of standard quercetin and ethanolic extract of $P$. peruviana fruit 
Table 2: Rf values for ethanolic extract of $P$. peruviana fruit

\begin{tabular}{|c|c|c|c|c|c|c|c|c|}
\hline S. No. & Start Rf & Start height & $\operatorname{Max} R f$ & Max height & Height\% & End $R f$ & End height & Area\% \\
\hline Standard & - & - & - & - & - & - & - & - \\
\hline Track 1 & 0.65 & 3.1 & 0.7 & 24.6 & 100 & 0.75 & 0.8 & 100 \\
\hline Track 2 & 0.63 & 1 & 0.69 & 299.5 & 100 & 0.71 & 0.6 & 100 \\
\hline Track 3 & 0.63 & 1.6 & 0.69 & 406 & 100 & 0.72 & 0.6 & 100 \\
\hline Track 4 & 0.64 & 10.8 & 0.69 & 406 & 100 & 0.72 & 0.6 & 100 \\
\hline Track 5 & 0.64 & 8.5 & 0.69 & 471.3 & 100 & 0.72 & 0.1 & 100 \\
\hline Track 6 & 0.64 & 6 & 0.69 & 480.8 & 100 & 0.72 & 0.3 & 100 \\
\hline Test Solution & - & - & - & - & - & - & - & - \\
\hline Track 7 & 0.65 & 0.9 & 0.68 & 12.6 & 100 & 0.72 & 3.7 & 100 \\
\hline Track 8 & 0.65 & 0.8 & 0.7 & 26.1 & 100 & 0.73 & 1.5 & 100 \\
\hline Track 9 & 0.65 & 0 & 0.7 & 58.4 & 100 & 0.74 & 0.2 & 100 \\
\hline Track 10 & 0.65 & 0.3 & 0.69 & 61.5 & 100 & 0.74 & 0.3 & 100 \\
\hline Track 11 & 0.68 & 0.2 & 0.73 & 54.6 & 100 & 0.76 & 0 & 710.5 \\
\hline Track 12 & 0.64 & 0 & 0.69 & 84.7 & 100 & 0.73 & 0.4 & 100 \\
\hline
\end{tabular}

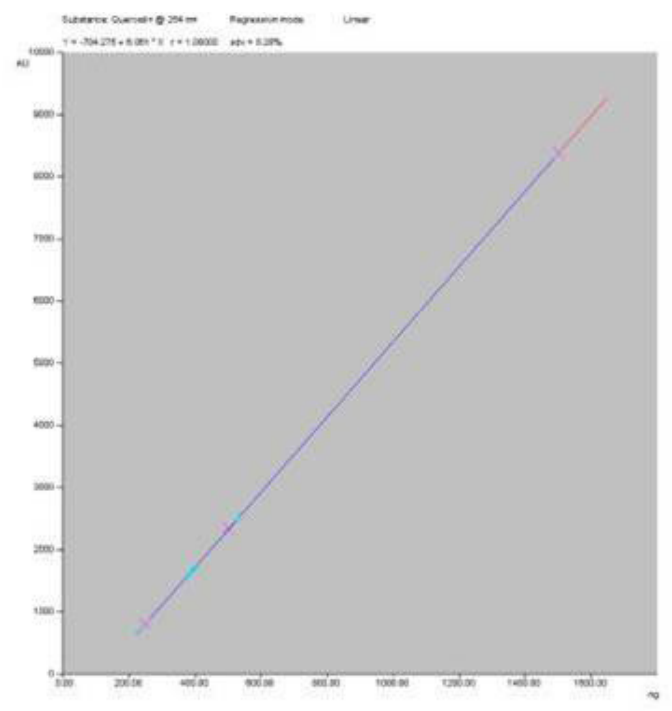

Fig. 4: Calibration curve of quercetin

which has directly reduced the molybdenum (IV) complex to molybdenum (V) complex, by the formation of green color phosphate/Mo (V) complex; it is measured by spectrophotometer at $695 \mathrm{~nm}$. A known antioxidant ascorbic acid act as the standard, the antioxidant activity of the ethanolic extract was calculated by the standard curve of ascorbic acid, which was comparatively more effective than the ethanolic extract of $P$. peruviana fruit. The maximum activity of the ethanolic extract was found to be $27.5 \pm 1.04$ and $31.7 \pm 0.8$, at 200 and $250 \mu \mathrm{g} / \mathrm{mL}$, were as standard ascorbic acid. At the same concentration, 200 and $250 \mu \mathrm{g} / \mathrm{mL}$ exhibited $34.25 \pm 0.8$ and $39.7 \pm 0.85$, respectively. These results indicated that the ethanolic extract of $P$. peruviana fruit had a notable amount of antioxidant (Table 3). Anyhow, a maximum reduction was attained at a higher concentration of $250 \mu \mathrm{g} / \mathrm{mL}$, compared to standard ascorbic acid. Ethanolic extract of P. peruviana
Table 3: Total antioxidant scavenging activity of ethanolic extract of P. peruviana fruits

\begin{tabular}{lll}
\hline S. No. & $\begin{array}{l}\text { Concentration } \\
(\mu \mathrm{g} / \mathrm{mL})\end{array}$ & $\begin{array}{l}\text { Total antioxidant activity } \\
(\%)\end{array}$ \\
\hline 1 & 50 & $21.3 \pm 0.55$ \\
2 & 100 & $24.5 \pm 0.64$ \\
3 & 150 & $26.8 \pm 0.6$ \\
4 & 200 & $32 \pm 0.8$ \\
5 & 250 & $35.2 \pm 0.9$ \\
\hline
\end{tabular}

Values were performed in triplicates and represented as mean \pm SD fruit was found to exhibit a high antioxidant capacity. The antioxidant assay has been most successfully applied to quantify vitamin $\mathrm{E}$ in $P$. peruviana fruit.

\section{DPPH Scavenging Activity of Ethanolic Extract of P. peruviana Fruits}

In the present study, the percentage of the scavenging effect on the DPPH $\bullet$ radical simultaneously increased the concentration of ethanolic extracts from 50 to $250 \mu \mathrm{g} / \mathrm{mL}$. The inhibition percentage of ethanolic extract exhibited from 14.5 at $50 \mu \mathrm{g} / \mathrm{mL}, 31.7$ at $250 \mu \mathrm{g} / \mathrm{mL}$, is shown in Fig. 5. The maximum DPPH scavenging activity (31.7\%) was observed at $250 \mu \mathrm{g} / \mathrm{mL}$ concentration. From the results, it shows that the species, $P$. peruviana fruits possess hydrogen donating capabilities and scavenges free radicals.

\section{Reducing Power Assay of Ethanolic Extract of P. peruviana Fruits}

Fig. 6 shows the reducing power of ethanolic extract of P. peruviana fruit. The reduced capacity of ethanolic extract was evaluated by measuring the transformation of potassium ferricyanide $\mathrm{K}_{3}\left[\mathrm{Fe}(\mathrm{CN})_{6}\right]$ into potassium ferrocyanide $\mathrm{K}_{4}\left[\mathrm{Fe}(\mathrm{CN})_{6}\right]$; it is reacting with $\mathrm{FeCl}_{3}$ to form ferric ferrous complex $\left(\mathrm{Fe}^{3+} \leftrightarrow \mathrm{Fe}^{2+}\right)$, which is measured 


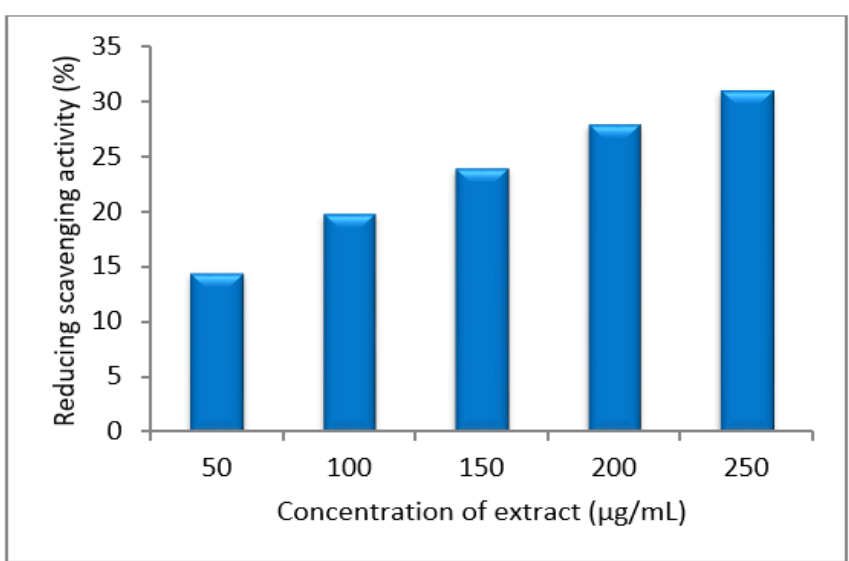

Fig. 5: DPPH scavenging activity of ethanolic extract of $P$. peruviana fruits; each value represents mean \pm SD

at $700 \mathrm{~nm}$. This is due to the presence of reductants in ethanolic extracts, which is acting as an antioxidant, providing/donating a hydrogen atom, and splitting the chain of free radicals. The percentage of reductive capacity of ethanolic extract increases with the increasing amount of concentration at 50,100,150,200, and $250 \mu \mathrm{g} / \mathrm{mL}$, reducing power was around $7.3,12.1,14.9,18.4$, and $22.8 \%$, respectively.

\section{DiscuSSION}

A free radical is a molecule with an unpaired electron, and is involved in parasitic and bacterial infections, inflammation, lung damage, cardiovascular disorders, reperfusion injury, neoplastic diseases, aging, and atherosclerosis. ${ }^{[14]}$ They are also involved in autoimmune disorder, like rheumatoid arthritis. ${ }^{[15]}$ The results demonstrated that the P. peruviana fruit extracts possess free radical scavenging activity in vitro models, like $\mathrm{DPPH} \bullet$, reducing power assay. Phytochemical compounds are synthesized during the metabolic processes; it poses various pharmacological activities. It is, otherwise, called as secondary metabolites. Most of the secondary metabolites have anti-cancer activities. The secondary metabolic compounds are quinines, alkaloids, tannins, glycosides, phenols, flavonoids, carbohydrates, and athraquinones. Anion radicals present in flavonoids serve as health-promoting compounds. ${ }^{[16]}$ Flavonoids are a group of polyphenolic compounds, which exhibit several biological effects, such as, anti-inflammatory, anti-allergic, anti-cancer, anti-ulcer, anti-viral, and anti-hepatotoxic activities. Phenolic compounds and flavonoids have the ability to scavenge the reactive $\mathrm{O}_{2}$ species because of the presence of phenolic hydroxyl groups, and so they are powerful antioxidants. ${ }^{[17-18]}$

It was found that the phytochemical analysis of P. peruviana fruit extract contained alkaloids, flavonoids, saponins, phenols, tannins, and anthraquinones contents. Anion radicals present in flavonoids serve as healthpromoting compounds. Flavonoids are phenolic compounds

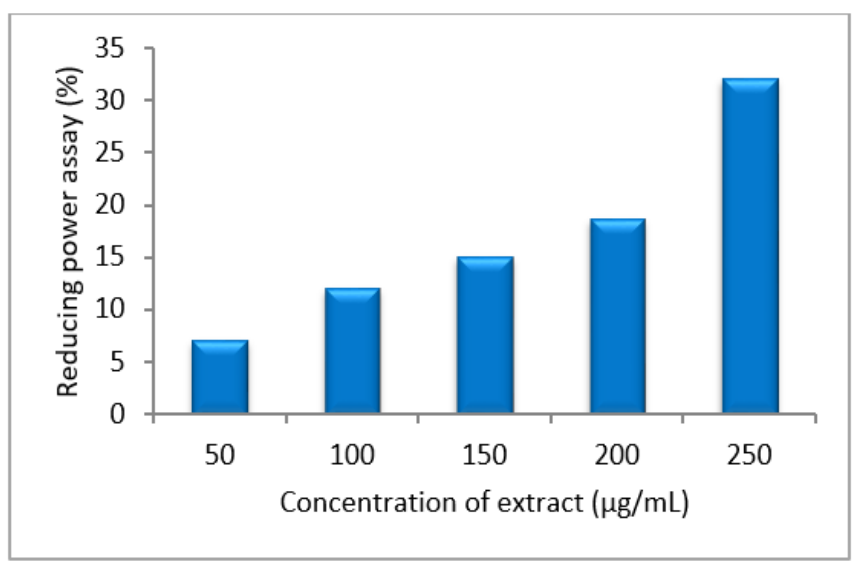

Fig. 6: Reducing power assay of ethanolic extract of $P$. peruviana fruits; each value represents mean $\pm \mathrm{SD}$

that act as antioxidants or free radical scavengers or free radical terminator. Since these compounds were found to be present in the ethanolic extracts, it might be responsible for the potent antioxidant capacity of $P$. peruviana fruit. Medicinal plants rich in secondary metabolites, like phenolic compound, terpenoids, alkaloids, and sulfurcontaining compounds and other chemical constituents, which have been extensively used in drug and various pharmaceutical industry. Flavonoids exhibited a wide range of biological activities, such as, antioxidant, antiinflammatory, antimicrobial, anti-angiogenic, anti-cancer, and anti-allergic activity. ${ }^{[19]}$

HPTLC is a rapid, simple, and accurate method for developing the quantitative estimation of quercetin present in the dried fruit powder of $P$. peruviana has been developed. Quantitative analysis experiments to provide more information about many bioactive compounds present in the plant material, which is generally responsible for the pharmacological effect, like antioxidant, antibacterial, anti-inflammatory, antimutagenic, anticarcinogenic, anti-viral, and antitumor effects. ${ }^{[20]}$ The result indicated that enabled good resolutions and shapes of the peak, short analysis time of quercetin from P. peruviana fruit. Similarly, the identification of quercetin by HPTLC and TLC studies, has also has been reported by many reviewers. ${ }^{[21,22]}$

In healthy individuals, free radicals are produced spontaneously as a byproduct of metabolic process in biological systems, which was balanced by an antioxidant defense system; however, it can cause tissue damage and leading to severe clinical complications, particularly cancer, chronic inflammation, diabetes, and neurodegenerative disorder. ${ }^{[23,24]}$ Newer development in biomedical sciences clearly explains the mechanism of free radicals mediated carcinogenesis. Antioxidants are the compounds that scavenge harmful free radicals.

The effect of antioxidants on DPPH radicals is thought to be due to their hydrogen donating ability. ${ }^{[25]}$ Generally, the antioxidant properties of these ethanolic extract of $P$. peruviana fruits were found to be concentration- 
dependent. DPPH assay is one of the universally accepted methods for analyzing the antioxidant capacity of various natural plant products and food because it is quick, easy, low cost, and reliable, and does not require a special reaction and tools. DPPH is a stable violet-colored free radical; it becomes colorless or the yellow-colored diphenyl-picryl hydrazine when neutralized. DPPH radicals react with appropriate reducing agents or hydrogen donors, and the electrons become paired with reductants. Finally, the purple color fades or disappears in the solution due to the conversion to diphenyl-picryl hydrazine resulting in a decrease in absorbance. DPPH radical reduction can be observed by the decrease in absorbance, which is measured at $517 \mathrm{~nm}$. DPPH radicals reduce by their hydrogen donating ability is reduced by phenolics and flavonoids compounds, reported by Prasad et al. ${ }^{[26]}$

The reducing power of $P$. peruviana fruit extract was found to be a more powerful reducing agent and potent hydrogen donating ability. Accordingly, P. peruviana fruits showed the presence of flavonoids, which may react with the free radicals to stabilize and terminate from the free radical chain reaction. ${ }^{[27]}$ The antioxidant activity of the ethanolic extract of $P$. peruviana fruits was found to be more effective.

\section{CONCLUSION}

The results of the present study suggest that the plant has a potential source of natural antioxidant or free radical scavenging activity. Further studies are needed for the isolation and characterization of antioxidant compounds, and also, in vivo studies are needed for understanding their mechanism of action as antioxidants.

\section{ACKNOWLEDGEMENT}

The authors are thankful to Dr. S. John Britto, who authenticated the plant.

\section{REFERENCES}

1. Randhir R, Lin YT, Shetty K. Stimulation of phenolics, antioxidant and antimicrobial activities in dark germinated mung bean sprouts in response to peptide and phytochemical elicitors. Process Biochem. 2004;39:637-646.

2. Siggurder Ingvarsson. Cancer introduction. Cancer Biology. 2001;11:323-325.

3. Alugoju Phaniendra, Dinesh Babu Jestadi, Latha Periyasamy. Free Radicals: Properties, sources, targets, and their implication in various diseases. Indian J Clin Biochem. 2015;30(1):11-26.

4. Kovacic P, Jacintho JD. Mechanisms of carcinogenesis: Focus on oxidative stress and electron transfer. Curr Med Chem. 2001;8(7):773-796.

5. Block g, Jensen DJ, Morrow JD, Holland N, Norkus EP, Milne gL, et al. Vitamin C treatment reduces elevated C-reactive protein. Free Radic Biol Med. 2009;46(1):70-77.

6. Licodiedoff S, Kozlowski LAD, Ribani RH. Flavonoid rates of gosseberry fruits Physalis peruviana determined by HPLC through the optimization and validation of the analytic method. Int J Food Sci Nutr Eng. 2013;3(1):1-6.

7. Wu SJ, Nq LT, Huang YM, Lin DL, Wang SS, Huang SN, et al. Antioxidant activities of Physalis peruviana. Biol Pharm Bull. 2005;28(6):963-966.

8. Zavala D, Mauricio Q, Pelayo A, Posso M, Rojas J, Wolach V. Cytotoxic effect of Physalis peruviana (capuli) in colon cancer and chronic myeloid leukemia. An Fac Med Lima. 2006;67(4):283-289.

9. Lan Q, Zhnag L, Shen M, Jo WJ, Vermeulen R, Li g, et al. Large scale evaluation of candidate genes identifies association between DNA repair and genomic maintenance and development of benzene hematotoxicity. Carcinogenesis. 2009;30(1):50-58.

10. Wu SJ, Chang SP, Lin DL, Wang SS, Hou FF, Ng LT. Supercritical carbon dioxide extract of Physalis peruviana induced cell cycle arrest and apoptosis in human lung cancer H661 cells, Food Chem Toxicol. 2009;47(6):1132-1138.

11. Vega galvez A, Zura BL, Lemus MR, Martinez MJ, Quispe FI, Puente L, et al. Influence of drying temperature on dietary fibre, rehydration properties, texture and microstructure of cape gooseberry ( Physalis peruviana L.). Jour Food Sci and Tech. 2013;52(4):23042311.

12. Sirwaiker AR, Rajendran K, Punitha ISR. In vitro antioxidant studies on the benzyl tetra isoquinone alkaloid. Biol. Pharm. Bull. 2006;29(9):2079-2080.

13. Blois MS. Antioxidant determinations by the use of a stable free radical. Nature, 1958;181:1199-1200.

14. Rice Evan CA, Burdon RH. Free radical damage and its control. Elsevier Science BV Netherlands. 1994;28:125.

15. Rao MS, Raman MV. Biochemical Systematics and Ecology. 2004;32:447-448.

16. Hausteen B. Flavonoids, a class of natural products of high pharmacological potency. Biochem Pharm. 1983;32:1141-1148.

17. Cao g, Sofic E, Prior RL. Antioxidant and pro-oxidative behavior of flavonoids: Structure activity relationships. Free Radical. Biol. Med. 1997;22:749-760.

18. Umamaheswari $\mathrm{M}$, Chatterjee TK. In vitro antioxidant activities of the fractions of Coccinia grandis L. leaf extract. Afr J Tradit Complemen. Altern Med. 2007;5(1):61-73.

19. Soares JR, Dinis TC, Cunha AP, Almedia LM. Antioxidant activities of some extracts of Thymus zygis. Free Radic Res. 1997;26(5):469-478.

20. Fraisse A, Temmam S, Deboosere N, Guillier L, Delobel A, Maris P, et al. Comparison of chlorine and peroxyacetic-based disinfectant to inactivate Feline calcivirus, murine nonovirus and hepatitis A virus on lettuce. Int J Food Microbiol. 2011;151(1):98-104.

21. Chithambara MKN, Vanitha A, Mahadeva SM, Ravishankar GA. Antioxidant and antimicrobial activity of Cissus quadrangularis $\mathrm{L}$ J Med Food. 2003;6(2):99-105.

22. Prieto P, Pineda M, Aquilar M. Spectrophotometric quantitation of antioxidant capacity through the formation of a phosphomolybdenum complex: specific application to the determination of vitamin E. Anal Biochem. 1999;269(2):337-341.

23. Yazdanparast R, Bahramikia S, Ardestani A. Nasturtium oficinale reduces oxidative stress and enhances antioxidant capacity in hypercholesterolaemic rats. Chem Biol Interact. 2008;172(3):176-184.

24. Frankel N, German JB. Antioxidants in foods and health: Problems and fallacies in the field. J Sci Food Agric. 2006;86(13):1999-2001.

25. Sharififar F, dehghn-Nudeh G, Mirtajaldini M. Major flavonoids with antioxidant activity from Teucrium polium L. Food Chem. 2009;112:885-888

26. Prasad KN, Divakar S, Shivamurthy GR, Aradhya SM. Isolation of a free radical-scavenging antioxidant from water spinach (Ipomoea aquatica Forsk). J Sci Food Agri. 2005;85(9):1461-1468.

27. Jadhav SJ, Nimbalkar SS, Kulkarni AD, Madhavi DL. Food antioxidants technological: toxicological and health perspectives. 1st ed. CRC Press. New York: Dekker; 1996. p. 5-63.

HOW TO CITE THIS ARTICLE: Venkatesan S, Somasundaram A, Rengaraj S. Evaluation of in vitro antioxidant activity and high-performance thin-layer chromatography finger printing analysis of Physalis peruviana fruits. Int.J.Pharm. Sci. Drug Res. 2020;12(4):384-389. D0I: 10.25004/IJPSDR.2020.120411 